\title{
Correlates of youth internal migration and employment in Uganda
}

\author{
Abel Nzabona, John Bosco Asiimwe, Christian Kakuba, Richard Tuyiragize \& \\ John Mushomi
}

Centre for Population and Applied Statistics, Makerere University

Kampala, Uganda

Email: abel.nzabona@gmail.com

\begin{abstract}
Background: Young people continue to gravitate from rural to urban Uganda. Whereas studies on drivers of this mobility abound, less is known about the predictors of internal migration and employment. This study investigated the correlates of youth migration and employment.

Data and methods: Primary data were collected from I,537 respondents. Binary and multinomial logistic regression models were fitted to predict migration and employment status, respectively.

Findings: Being an older youth increased the odds of outmigration and chances of employment. Hailing from a rural environment increased chances of outmigration. The never married youths were less likely to be self-employed but more likely to be paid employees than their married counterparts. Females were less likely to be employed than males.

Conclusion: Age, home environment and sex were significant correlates of migration and employment. We recommend improvement in rural conditions and strengthening programmes that address the gender gap in employment opportunities.
\end{abstract}

Keywords: Youth Internal Migration Employment Uganda

\section{Introduction}

Internal migration in Uganda pre-dates the country's independence time and indeed has occurred over aeons of years. Rural population re-distribution has been profound, sustained and enduring since the early $20^{\text {th }}$ century (Kabera 1978). Intra-national population mobility has been documented using empirical data from primeval national censuses of 1948, 1959 and 1969 (Langlands 197I). Past rural population redistribution is said to have largely been influenced by a number of environmental and human factors. Outstanding among the environmental factors were soil quality, availability of ground water, distribution of rainfall, the intensity of the dry season and biotic life. The sleeping sickness epidemic across the country during late $19^{\text {th }}$ and early $20^{\text {th }}$ centuries is said to have been a major factor in laying waste large areas either directly or through control regulations which necessitated the removal of surviving population.

Disparities in land availability is said to have been one of the drivers of internal population redistribution especially regarding movements between Kigezi, Toro and Bunyoro sub-regions of the western region of the country (Hartter et al. 2015; Kabera 1983). Owing to population pressure and colonial government policy, large numbers of people from Kigezi sub-region gradually moved towards Toro sub4621 region (an area with relatively less population-land pressure). Alongside the land question was the quest, on the part of some out-migrants from Kigezi, for finding gainful employment in the Kilembe Copper mines which was a thriving extractive economy at the time. The corollary of the Kigezi outmigration was the rise of dense settlement and subsistence agriculture effected by tens of thousands of smallscale farming households since the last half of the twentieth century (Hartter et al. 2015). The scholars further posit that population density closer to the current Kibale National Park grew to I.5 times higher than places more distant from the park. Migration to areas near the park is said not necessarily to have been influenced by economic benefits accruing from the park itself, but rather by important push and pull factors at different scales.

While environmental and extractive industry factors continue to be relevant to today's internal migration pattern, contemporary migration seems to be much more explicable within the context of commercial considerations. There are dominant migration streams moving, not so much to rural destinations, but comparatively more to centres of agglomerations as well as real and upcoming growth poles (Ntozi et al. 20ll). Young people, predominantly the youth sub-group, appear to take

http://aps.jorunal.ac.za 
up the largest proportion of the population on the move.

\section{Literature review}

Uganda's National Youth Policy, defines youths as all young males and females aged 12 to 30 years. It recognizes the youths as persons of great emotional, physical and psychological changes that require societal support for a safe passage from adolescent to full adulthood (MoGLSD 2016). As at 2015, 64 percent of the labour force was aged between 15 and 29 years (UBOS 2016). This implies that the majority of individuals in the labour force fall within this youth category. The structure of the population is attributed to mainly persistently high fertility rates, coupled with falling mortality rates that have led to a growing youthful population. Recent studies indicate that Uganda's fertility rate stands at 5.4 per woman(UBOS 2016).

Uganda's population size has gradually increased from a mere 2.5 million in 1911 to 34.6 million in 2014 (UBOS \& ICF 20I8) and the average annual growth rate has staggered between 2.0 to 3.2 percent since 1931. Projections indicate the country will have 102 million persons by 2050 (UNDESA 20I5). Youths as a population sub-group are at the centre of the current and future large population size.

National studies indicate prevalence of migration differentials by various socio-demographic characteristics. The 2014 Uganda census shows that almost 20 percent of the youths had lived in other districts by the time of the census (UBOS 2016). Migration by location or type also shows that there was more rural-rural migration in Uganda with female youths leading in numbers compared to their male counterparts. In terms of the type and location of migration, migration was categorized as ruralurban, urban-urban, urban-rural and rural-rural. More male youths migrated in the urban-urban and urban-rural categories compared to the female youths. On the other hand, more female youths migrated in the category of rural-urban than male youths. Other studies have revealed high levels of temporary labour migration linking rural areas to metropolitan areas and secondary urban places (Collinson et al. 2016).

A recent Uganda National Household Survey indicates that close to a quarter of the population had lived in another place before their residence by survey time (UBOS 2017). More females than males had lived in another place during the reference period. The youth cohort (18-24 years) had the highest percentage of persons who had lived in another place within the 5 years prior to the survey. Kampala City had the highest percentage of persons who had lived in another place which is perhaps expected due to the pull factors while Kigezi, Elgon and Bukedi which are predominantly rural areas had the lowest. Other studies have indicated that migration status (non-migrant/recent migrant) is associated with variations in fertility level among the women population (Banougnin et al. 2018).

There are various push and pull factors which influence youths to migrate internally. The push factors include economic reasons such as land shortage (in the case of rural areas), poor market access and unemployment as well as personal reasons (Oucho 2007). A Ugandan study indicates that overall, four in every ten individuals migrate for income reasons while about a quarter follow or join family (UBOS 2010). Nearly one in every five individuals migrate due to marriage. Disaggregation of reasons for migrating by sex indicates that males were twice as likely to migrate for income reasons than their female counterparts. The findings also show that migration for income reasons was highest in the 35-44 age group and lowest in the less than 18 years age group. The main reason behind the migration of the majority of migrants aged less than 18 years was to follow/join family.

Censuses and Surveys in Uganda and some other African countries regularly collect rich data on fertility and mortality but comparatively under-represent migration issues (Oucho \& Gould 1993). The instruments used in these studies almost always contain very few questions that can be used for rigorous migration analysis. Consequently, these traditional sources are of limited use for rich migration analysis. This study aimed to engage with deeper reflections on migration in the country. The objective was to examine the correlates of youth internal migration and employment and contribute to enhanced understanding of links between migration and development.

\section{Data and methods}

The paper uses primary data collected in a 2017 national cross sectional survey. A structured questionnaire was designed and used to collect a range of data pertaining to background characteristics, living conditions and employment status of the youths. At the time of the survey, Uganda comprised 112 districts spread over four broad national regions namely; Central Region, Eastern Region, Northern Region and Western Region. From each region, two districts were selected at random. These were Masaka and Mubende (Central Region), Busia and Mbale (Eastern Region), Arua and Gulu (Northern Region) and Mbarara and Hoima (Western Region). Kampala Capital City was purposively selected as the ninth district owing to its primate city status, destination of 
large in-migrants and prevalence of complex employment dynamics.

From the nine districts, 1537 respondents were interviewed. This number was proportionately allocated to the 9 districts factoring in the proportion of youths in each district as informed by the National Population and Housing Census (UBOS 20I6). Simple random sampling was used to select the youths from each district for interview. This study operationally considered youths to be persons aged 18-35 years and this population subgroup constitutes about 33 percent of the population in the selected districts.

Regarding Research Assistants, shortlisted persons were interviewed of which 48 enumerators and 9 supervisors were ultimately recruited, trained and deployed to collect the data. A pre-test was carried out in November 2017 followed by the main data collection exercise in the subsequent month. Both exercises used Computer Assisted Personal Interviewing (CAPI) method. Uploads of data were effected onto the Survey CTO server where information could be accessed in real time.

STATA 13 software was used to analyze the association between socio-demographic factors and migration status. The software was also used to analyse predictors of migration and employment status. Binary logistic regression model was fitted with respect to migration status (migrant/nonmigrant) while multinomial logistic regression was employed in analyzing employment status (not working, self-employed, paid employee and casual worker).

\section{Results}

\section{Background characteristics of respondents}

Results in Figure I indicate that the majority of the youths interviewed were aged 2I-25 (40\%) followed by those in the $26-30$ age bracket (29\%) while those aged $3 \mathrm{I}-35$ were I $4 \%$. The mean age of respondents was 25 years. There were more male youths (56\%) than female youths (44\%). Just over half (55\%) of the youths were never married; the proportion of married was slightly over a quarter (27\%). The majority of the youths belonged to the Catholic religious persuasion (36\%) followed by Anglicans and Muslims (28\% and $12 \%$, respectively). This relative distribution of youths by religion echoes the distribution of the entire population by religion (UBOS, 2016).

Figure I further indicates that just over half of the youths were household heads (54\%) while about 3 out of $10(29 \%)$ were either spouses or children to household heads. Interestingly, the proportion of youths who were friends of the household head was only 4\%; a possible indicator of insignificance of friendship vis-a-vis kinship in household composition.

Most of the youths reported the rural area as their home place $(48 \%)$ and the proportion decreased with increasing nominal description of urbanization ( $28 \%$ for small rural town, $21 \%$ for municipality and only $3 \%$ for large city). Regarding employment, just under half $(46 \%)$ reported being self-employed while slightly under one-quarter $(23 \%)$ were paid employees and just under one-fifth (I8\%) were paid casual workers. About I in 10 (13\%) were not working. 


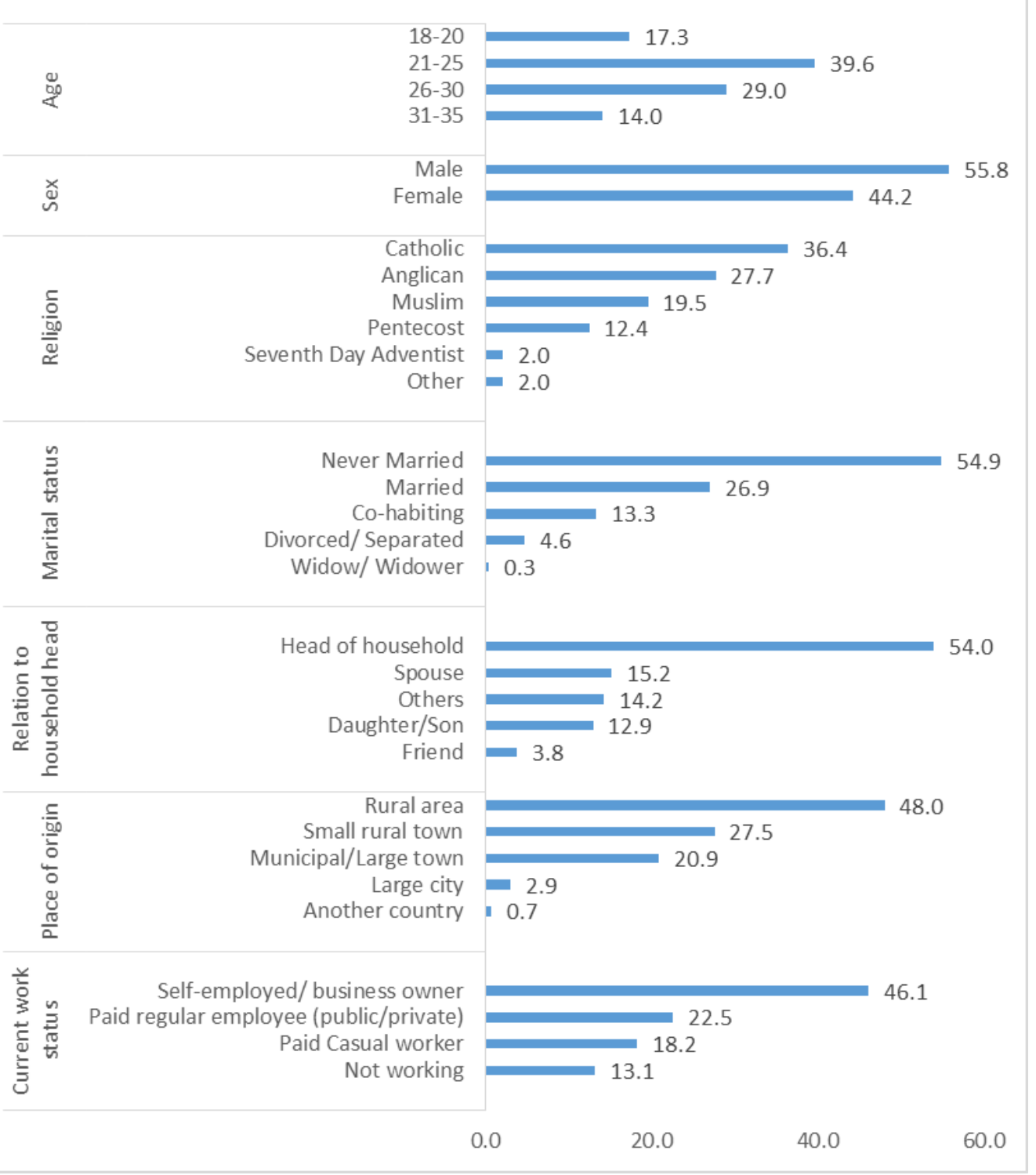

Figure I: Percent distribution of youths by background characteristics

Association between migration status and sociodemographic factors

Migration status can be associated with individual's socio-demographic characteristics. Table I shows that age was significantly associated with migration status. About 8 in $10(82 \%)$ of those aged $31-35$ were migrants while the corresponding percentage among those aged 18-20 was just under 7 in 10 (68\%). Table I further indicates that marital status, relationship to household head, education and home place were also significantly associated with migration status.

Table I: Percent distribution of youths by migration status and by background characteristics

\begin{tabular}{lccc}
\hline Characteristic & Migrant & Non-migrant & Number \\
\hline Age & & & \\
$18-20$ & 67.7 & 32.3 & 266 \\
$2 \mid-25$ & 75.2 & 24.8 & 609 \\
$26-30$ & 76.9 & 23.1 & 216 \\
$3 \mid-35$ & 81.5 & 18.5 & \\
$X^{2}=\mid 3.3 ; p=0.004$ & & & 857 \\
\hline Sex & & & 680 \\
Male & 75.0 & 25.0 & \\
Female & 75.6 & 24.4 & \\
$X^{2}=0.06 ; p=0.801$ & & & 414 \\
\hline Marital status & & & \\
Married & 78.8 & 21.7 & 4624 \\
http://aps.journals.ac.za & & &
\end{tabular}




\begin{tabular}{lccc} 
Co-habiting & 83.8 & 16.2 & 204 \\
Divorced/separated/Widower & 73.7 & 26.3 & 76 \\
Never married & 71.9 & 28.1 & 843 \\
$X^{2}=15.3 ; p=0.002$ & & & 830 \\
\hline Relation to Household Head & & 20.8 & 233 \\
Head of household & 79.2 & 20.2 & 198 \\
Spouse & 79.8 & 54.6 & 58 \\
Daughter/Son & 45.4 & 17.2 & 218 \\
Friend & 82.8 & 19.3 & \\
Others & 80.7 & & 38 \\
$X^{2}=109.2 ; p=0.000$ & & & 404 \\
\hline Formal education level & & 15.8 & 775 \\
No education & 84.2 & 17.3 & 320 \\
Primary education & 82.7 & 27.6 & \\
Secondary education & 72.4 & 28.1 & 738 \\
Vocational/University & 71.9 & & 423 \\
$X^{2}=18.0 ; p=0.000$ & & & 321 \\
\hline Home environment & & 16.0 & 55 \\
Rural area & 84.0 & 27.9 & 1,537 \\
Small rural town & 72.1 & 38.9 & 34.6 \\
Municipal/large town & 61.0 & & 24.7 \\
Large town/other country & 65.4 & & \\
$X^{2}=70.3 ; p=0.000$ & & 75.3 & \\
\hline Total & & & \\
\hline
\end{tabular}

Association between employment status and socio-demographic factors

A person's employment status before and after migration can be associated with their sociodemographic characteristics. Table 2 indicates the socio-economic correlates of employment status for all youths in general and migrant youths in particular. Regarding all youths, the percentage of those who were not working decreased with age. Interestingly, the percentage of youths who were self-employed was higher among those who either did not pursue formal education or were educated up to just primary level than their counterparts with higher educational attainment. The predominance of engagement in informal sector, which does not necessarily require high educational skills, may explain the pattern.

Regarding migrant youths, Table 2 shows that among those whose paternal parents did not have formal education, just over one-fifth (22\%) were not working while the corresponding proportion among those whose paternal parents had primary education was 10 percent. Although the the level among those with parents of secondary and vocational/university education were relatively higher $(13 \%$ and $11 \%$ respectively), the level of not working was still much lower in comparison with no education. Employment status was also significantly associated with mother's education, Table 2 further shows that among migrant youths who had ever travelled abroad, the percentage who were not working was $7.3 \%$ while among those who had never travelled, the corresponding figure was 12.9 percent. Among the youths migrants who had ever worked before migrating to the current destination, those who were not working comprised 9 percent while among those who had never worked before migrating to the current place was 15.0 percent.

Table 2: Percent distribution of youths by employment status and by background characteristics

\begin{tabular}{|c|c|c|c|c|c|}
\hline \multirow[t]{2}{*}{ Characteristic } & \multicolumn{4}{|c|}{ Employment status } & \multirow[b]{2}{*}{ Numbe } \\
\hline & Not working & $\begin{array}{c}\text { Self- } \\
\text { employed }\end{array}$ & $\begin{array}{l}\text { Regular } \\
\text { employee }\end{array}$ & $\begin{array}{c}\text { Paid casual } \\
\text { worker }\end{array}$ & \\
\hline \multicolumn{6}{|c|}{ All Youths (migrant \& non-migrant) } \\
\hline \multicolumn{6}{|l|}{ Age } \\
\hline $18-20$ & 24.4 & 24.4 & 20.3 & 30.8 & 266 \\
\hline $21-25$ & 11.8 & 41.9 & 26.8 & 19.5 & 609 \\
\hline $26-30$ & 11.0 & 55.8 & 21.3 & 11.9 & 446 \\
\hline $31-35$ & 7.4 & 64.8 & 15.7 & 12.0 & 216 \\
\hline
\end{tabular}


$X^{2}=19.4 p=0.000$

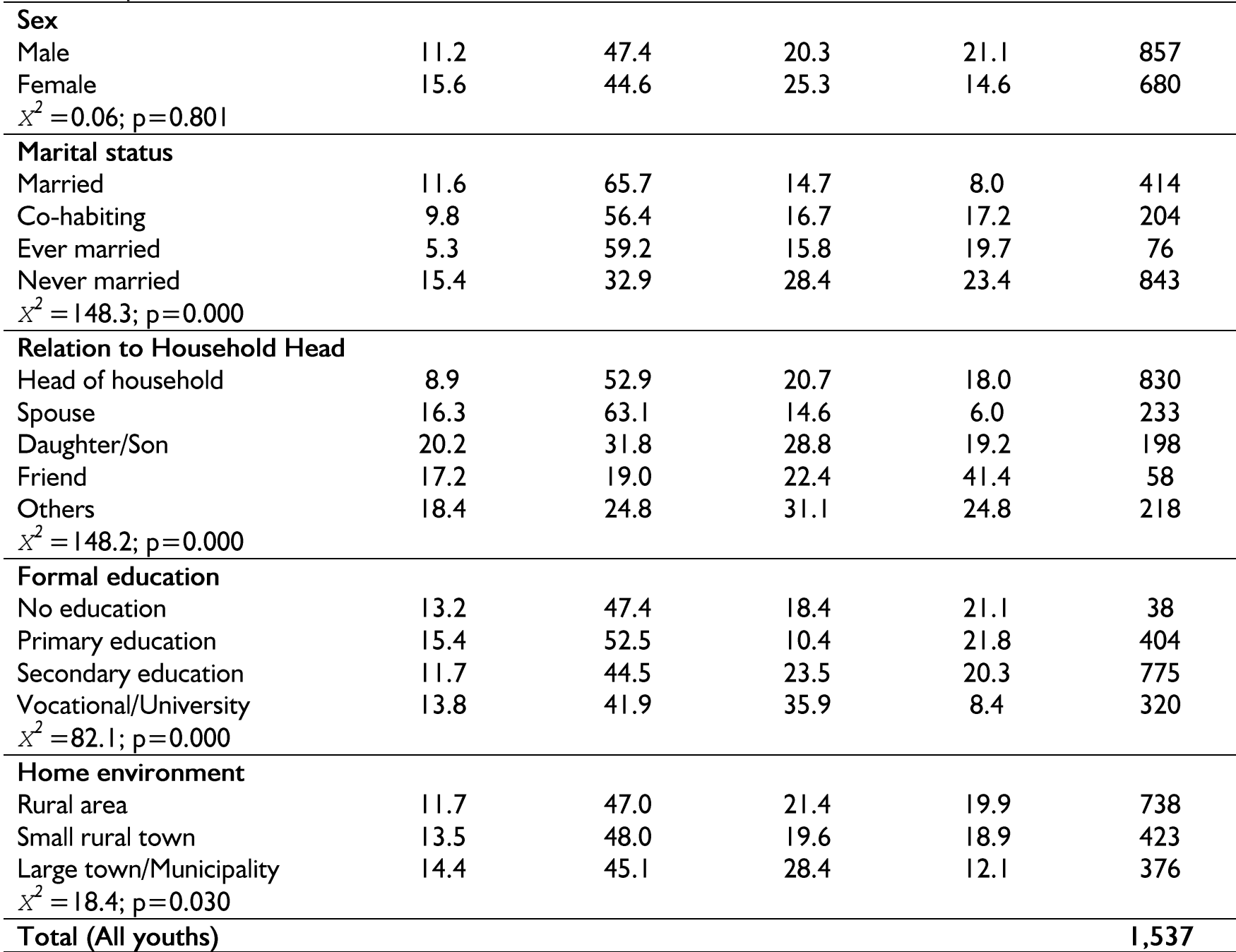

Migrant youths

Father's education

No education

Primary education

21.7

51.1

9.8

17.5

143

Secondary education

9.8

52.7

22.7

14.8

317

Vocational/University

13.0

42.9

25.6

238

11.2

39.2

18.5

Do not know

10.4

46.5

29.4

20.3

143

$X^{2}=38.2 ; p=0.000$

\section{Mother's education}

No education

$16.6 \quad 51.8$

20.9

22.2

316

Primary education

Secondary education

Vocational/University

$11.6 \quad 48.9$

$51.8 \quad 15.0$

16.6

247

$11.5 \quad 40.2$

24.6

14.9

362

$11.3 \quad 38.0$

27.3

21.1

209

Do not know

10.1

48.1

35.2

15.5

71

$X^{2}=36.1 ; p=0.000$

\section{International work travel}

Ever travelled abroad

Never travelled abroad

$X^{2}=12.8 ; p=0.005$

Pre-migration work

Ever worked

Never worked

$X^{2}=24.8 ; p=0.000$

$7.3 \quad 61$

17.5

24.3

268

Total (Migrant youths)

61.8

18.7

12.2

123

http://aps.journals.ac.za

12.9

22.4

19.3

I,034

\section{1}

15.0

12.3

45.4

50.4

25.9

14.7

530

44.3

18.8

21.9

627

47.1

22.0

18.6

$\mathrm{I}, 15$


Predictors of migration status

Results from Binary Logistic Regression analysis show that age and home environment predicted migration status (Table 3). In comparison with youths aged 1820 , the odds of being a migrant were increased for those aged 2I-25 $(\mathrm{OR}=\mathrm{I} .6 ; p=0.007 ; \mathrm{Cl}=\mathrm{I} .136-$
2.246), 26-30 (OR=I.6; $p=0.022, \mathrm{Cl}=1.069-2.338)$ and 3I-35 (OR=2.I; $p=0.003 ; \mathrm{Cl}=1.290-3.543)$. Compared with youths whose home environment was large city, the odds of being a migrant were increased for those whose home area was rural environment $(\mathrm{OR}=2.6 ; p=0.002 ; \mathrm{Cl}=1.433-4.852)$.

\section{Table 3: Predictors of migration status}

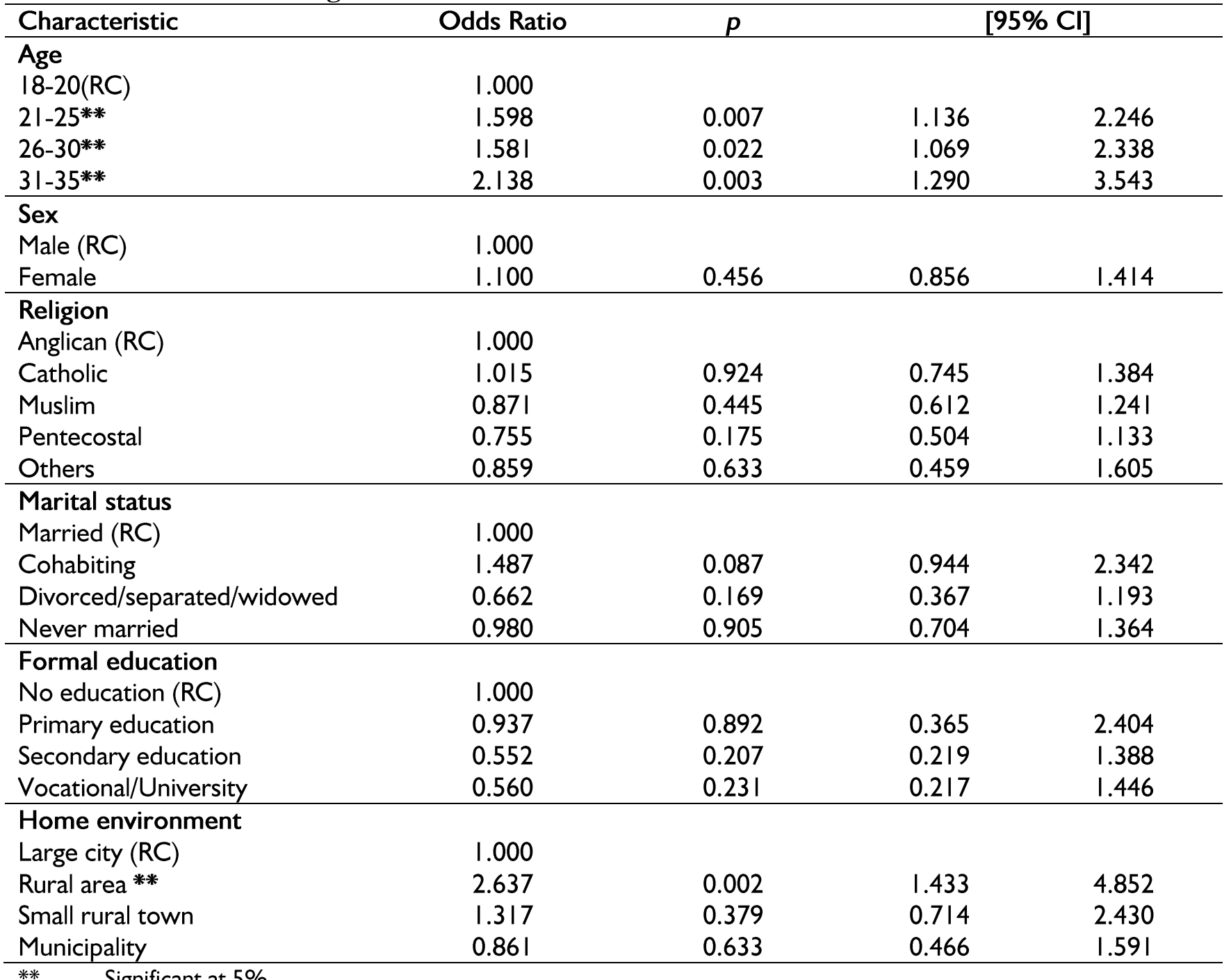

\section{Predictors of employment status}

Table 4 shows Multinomial Logistic Regression results of predictors of employment status. The factors are in reference to not working which is the base outcome.

Age, sex and marital status were the significant factors of self-employment. The chances of selfemployment were increased for persons aged $21-25$ $(\mathrm{RRR}=2.7 ; \quad \mathrm{Cl}=1.56-4.75), \quad 26-30 \quad(\mathrm{RRR}=3.8$; $\mathrm{Cl}=2.04-7.07)$ and $3 \mathrm{I}-35(\mathrm{RRR}=5.7 ; \mathrm{Cl}=2.49-\mathrm{I} 2.84)$ in comparison with their counterparts aged $18-20$. It is also shown that being female reduced the chances of self-employment in comparison with being male $(\mathrm{RRR}=0.6 ; \mathrm{Cl}=0.40-0.88)$. Being never married reduced the chances of self-employment in comparison with being married $(\mathrm{RRR}=0.5 ; \mathrm{Cl}=0.33$ 0.89).

In terms of paid regular employee, being aged between 2I-25 increased the chances of paid regular employment compared to being aged 18-20 $(R R R=2.2 ; \mathrm{Cl}=1.22-4.06)$. The chances were also higher and comparable for those aged $26-30$ and 31 $35(\mathrm{RRR}=3.0 ; \mathrm{Cl}=\mathrm{I} .53-6.00$ and $\mathrm{RRR}=3.0 ; \mathrm{Cl}=\mathrm{I} .16-$ 7.49 respectively).

Regarding paid casual worker, sex and marital status were significant factors. Just like with selfemployed, being female reduced the chances of being a paid casual worker compared to being male 
$(\mathrm{RRR}=0.5 ; \mathrm{Cl}=0.3 \mathrm{I}-0.76)$. Cohabiting $(\mathrm{RRR}=2.9$; $\mathrm{Cl}=\mathrm{I} .24-6.77)$, ever married $(\mathrm{RRR}=4.3 ; \mathrm{Cl}=\mathrm{I} .18$ -

I6.I3) and never married ( $R R R=2.5 ; C l=I .27-4.80)$ increased the chances of being a casual worker in comparison with being married.

Table 4: Multinomial logistic regression: Predictors of employment status

\begin{tabular}{|c|c|c|c|c|c|c|c|c|c|}
\hline \multirow[t]{2}{*}{ Characteristic } & \multicolumn{3}{|c|}{ Self-employed } & \multicolumn{3}{|c|}{ Regular employee } & \multicolumn{3}{|c|}{ Paid casual worker } \\
\hline & RRR & \multicolumn{2}{|c|}{$[95 \% \mathrm{Cl}]$} & \multirow[t]{2}{*}{ RRR } & \multicolumn{2}{|c|}{$[95 \% \mathrm{Cl}]$} & \multirow[t]{2}{*}{ RRR } & \multicolumn{2}{|c|}{$[95 \% \mathrm{Cl}]$} \\
\hline \multicolumn{8}{|c|}{ Not working (base outcome) } & & \\
\hline \multicolumn{10}{|l|}{$\begin{array}{l}\text { Age } \\
\text { I8-20\# }\end{array}$} \\
\hline $21-25$ & $2.72 * * * *$ & 1.56 & 4.75 & $2.23 * * * *$ & 1.22 & 4.06 & 1.26 & 0.72 & 2.20 \\
\hline $26-30$ & $3.79 * * * *$ & 2.04 & 7.07 & $3.03 * * * *$ & 1.53 & 6.00 & 0.92 & 0.47 & 1.82 \\
\hline $31-35$ & $5.65 * * *$ & 2.49 & 12.84 & $2.95 * *$ & 1.16 & 7.49 & 1.35 & 0.53 & 3.46 \\
\hline \multicolumn{10}{|l|}{ Sex } \\
\hline \multicolumn{10}{|l|}{ Male\# } \\
\hline Female & $0.59 * *$ & 0.40 & 0.88 & 0.80 & 0.51 & 1.23 & $0.48 * * *$ & 0.31 & 0.76 \\
\hline \multicolumn{10}{|l|}{$\begin{array}{l}\text { Marital status } \\
\text { Married\# }\end{array}$} \\
\hline Co-habiting & 1.19 & 0.61 & 2.35 & $1.6 \mid$ & 0.74 & 3.52 & $2.90 * *$ & 1.24 & 6.77 \\
\hline Ever married & 1.73 & 0.56 & 5.39 & 2.18 & 0.60 & 8.00 & $4.36 * *$ & 1.18 & 16.13 \\
\hline Never married & $0.54 * *$ & 0.33 & 0.89 & 1.73 & 0.98 & 3.06 & $2.47 * * *$ & 1.27 & 4.80 \\
\hline \multicolumn{10}{|l|}{ Education } \\
\hline \multicolumn{10}{|l|}{ No education\# } \\
\hline Primary education & 1.49 & 0.48 & 4.61 & 0.61 & 0.16 & 2.25 & 1.37 & 0.38 & 4.96 \\
\hline Secondary education & 2.08 & 0.66 & 6.50 & 1.62 & 0.44 & 5.95 & 1.87 & 0.51 & 6.87 \\
\hline Vocational/University & 1.06 & 0.32 & 3.50 & 1.37 & 0.36 & 5.29 & 0.56 & 0.14 & 2.30 \\
\hline \multicolumn{10}{|l|}{$\begin{array}{l}\text { Home environment } \\
\text { Rural area\# }\end{array}$} \\
\hline Small rural town & 1.03 & 0.65 & 1.65 & 0.84 & 0.50 & 1.42 & 0.88 & 0.52 & 1.50 \\
\hline Municipal/large town & 0.77 & 0.45 & 1.30 & 0.82 & 0.47 & 1.44 & 0.56 & 0.31 & 1.04 \\
\hline Large city & 1.08 & 0.37 & 3.10 & 0.50 & 0.14 & 1.77 & 0.47 & 0.12 & 1.89 \\
\hline \multicolumn{10}{|l|}{ Father's education } \\
\hline Primary education & 1.40 & 0.80 & 2.44 & 1.37 & 0.73 & 2.56 & 0.98 & 0.51 & 1.87 \\
\hline Secondary education & 0.92 & 0.52 & 1.62 & 1.00 & 0.54 & 1.87 & 0.86 & 0.45 & 1.63 \\
\hline Vocational/Higher & 0.92 & 0.44 & 1.93 & 1.11 & 0.51 & 2.42 & 1.55 & 0.68 & 3.54 \\
\hline \multicolumn{10}{|l|}{$\begin{array}{l}\text { Mother's education } \\
\text { No education\# }\end{array}$} \\
\hline Primary education & 1.01 & 0.61 & 1.68 & 1.37 & 0.77 & 2.41 & 0.87 & 0.48 & 1.57 \\
\hline Secondary education & 1.30 & 0.70 & 2.41 & 1.76 & 0.91 & 3.39 & 1.31 & 0.66 & 2.59 \\
\hline Vocational/Higher & 1.29 & 0.50 & 3.33 & 2.05 & 0.78 & 5.43 & 1.16 & 0.38 & 3.55 \\
\hline
\end{tabular}

**Significant at $5 \%$

****Significant at $1 \%$

\# Reference category

\section{Discussion}

Being 'older youth' appeared to increase the odds of migration in comparison with being teenager. Results indicate that for all ages, the youths above 20 were more likely to migrate than their counterparts below 20; with highest odds being for those above 30 . However the lower likelihood of teenage migration may not necessarily reflect absence of desire to venture out of the home environment. Rather, it is likely the teenagers were still pre-occupied with schooling in the local home environment. It is also http://aps.journals.ac.za probable teenagers first sought opportunities in their local environment and considered out-migrating later along the life-course. This could have arisen if their hopes were dashed or when they became successful and wanted to build on their successes in different environments. The latter scenario dovetails with the well-known phenomenon of stepwise migration (Schapendonk 2009; Adepoju 2004).

An interesting feature of this study is the emergence of the characteristic of the home environment as a significant predictor of migration status (while controlling for the usual demographic factors of population mobility and re-distribution). 
The youths in the relatively larger agglomerations and growth poles were less likely to migrate than their counterparts in the more rural settings. This suggests that, conversely, rural dwellers were much more likely to migrate than their urban counterparts. The movement out of rural areas could be towards urban areas or even other rural environments where growth poles are emerging (such as trading centres, welding points or roadside markets which are a common feature in rural Uganda). Adepoju (2013) has similarly observed that, contrary to common perceptions of the predominance of rural-urban migration, substantial rural-rural migration occurs in Sub-Saharan Africa as is often seen in the case of salaried employment in plantations or cash-crop areas.

Our finding that indicates rising chances for selfemployment and paid regular employment with age could be suggestive of the role played by social capital networks. As youths get older along the life-course, there could be a rise in the likelihood of acquiring friends, mentors and experience. These can constitute a sort of social capital that the migrants can draw upon to gain entry into, or consolidate their status in, the job market. Widening social networks that engender adaptation at destination have similarly been established in other studies (Massey et al, 1984).

Results indicate that the odds of being selfemployed and paid casual worker were consistently lower for females than males. Although the lowly educated females in Uganda tend to be visible more in the informal rather than formal sector, our findings show that their chances of engagement in casual paid activities were less than those of their male counterparts. This fits into the broader perspective of unequal opportunities that have characterized gendered work over the past years. Some people often use their personal or family money while others obtain bank loans to set up enterprises but this is often more difficult for women than for men. Other studies have similarly indicated prevalence of restrictions on female engagement in diverse incomegenerating activities. It is argued that restricted choice, limited contacts of women and physical segmentation of the labour market perpetuate forces that hinder women engagement in economic work within a low-income context and this often has worse outcomes for women than men (Mitra 2005).

Lastly, we found that marital status exerts influence on employment outcomes at destination. In comparison with married young people, the never married youths had less chances of being selfemployed. It is likely that the never married persons were also younger and with less accumulated experience and skills for entrepreneurship. It has 4629 been argued for example that female entrepreneurship is influenced by factors such as women educational background, employment experience, business skills and capital sources (Spring 2009) and that substantial movement from the informal to the formal sector is limited owing to limitations of entry requirements of capital, education or networks.

Like the ever married, the never married youths had a higher likelihood of being paid casual workers. The higher chances for engagement in paid casual work could stem from the fact that a substantial number of women are in informal work in which participation is most ideal for persons with less family commitments and restrictions at home. The never married are likely to fit better than their married counterparts into informal income-generating activities such as food vending, selling manufactured wares, commercial transport, taxi-touting and rendering late night bar services. In contrast, the married youths are less likely to be flexible and more restricted in time-utilisation and decision-making. Other studies have indicated that some women are unable to participate fully in the labour market because they are required to combine their household activities with income yielding jobs (Mitra 2005). Such women may be restricted to work in the neighbourhood of their residence and male family members may have had a say on the type and location of the work the females do.

\section{Conclusion and implications}

Age is a significant factor influencing both migration status and employment outcomes of the migration process. Overall 'older youths' are more likely to be migrants, self-employed and regular employees. Age should be one of the components of any strategies that seek to influence internal migration dynamics in the country. Rural environment as a significant predictor of migration status calls for programmes that address conditions in the rural home environment for better management of the youth migration process. The sex differentials in employment status calls for strengthened interventions that address prevalence of disproportionate opportunities between male and female youths for better national development.

\section{Limitations}

The Youth Migration and Employment Survey dataset which this study used, lacked a wide range of data on background characteristics of migrants. Data on some aspects of youth non-migrants were even more limited and this hindered engagement with detailed comparisons between migrant and non-migrant youths on all background characteristics. 


\section{Acknowledgements}

We are grateful to IDRC for funding the migration survey and granting access to the data used in the study. Gratitude is equally extended to the Centre for Basic Research, Centre for Population and Applied Statistics and the College of Business and Management Sciences, Makerere University for the enabling study environment.

\section{References}

Adepoju, A., 2013. An overview of rural migration and agricultural labour force structure in Africa. African Population Studies, I.

Adepoju, A., 2004. Trends in international migration in and from Africa. International migration: Prospects and policies in a global market, pp.5976.

Banougnin, B.H., Adekunle, A.O., Oladokun, A. and Sanni, M.A., 2018. Impact of internal migration on fertility in Cotonou, Benin Republic. African Population Studies, 32 (2).

Collinson, M.A. et al., 2016. Youth migration, livelihood prospects and demographic dividend: A comparison of the Census 201I and Agincourt Health and Demographic Surveillance System in the rural northeast of South Africa. African Population studies, 30 (2 Suppl), p.2629.

Hartter, J., Ryan, S. J., MacKenzie, C. A., Goldman, A., Dowhaniuk, N., Palace, M., ... \& Chapman, C. A., 2015. Now there is no land: a story of ethnic migration in a protected area landscape in western Uganda. Population and Environment, 36 (4), 452-479.

Kabera, J.B., 1983. Population out-migration and redistribution with reference to Bugisu and Kigezi. $\mathrm{PhD}$ Thesis. Makerere University.

Kabera, J.B., 1978. Rural population re-distribution in Uganda since 1900, Kampala.

Langlands, B.W., 197I. Population distribution in Uganda 1959-1969. East African Geographical Review, I97I(9), pp.59-68.
Mitra, A., 2005. Women in the urban informal sector: Perpetuation of meagre earnings. Development and Change, 36(2), pp.29I-3I6.

MoGLSD, 2016. Uganda National Youth Policy, Kampala.

Ntozi, J., Nzabona, A. \& Tumwine, F., $201 \mathrm{l}$. Evolution of Migration in Uganda since the 1950s. In J. Oucho, ed. Migration in the Service of African Development: Essays in Honour of Professor Aderanti Adepoju. Ibadan: Safari Books Limited, pp. 343-360.

Oucho, J.O., 2007. Migration and regional development in Kenya. Development, 50(4), pp.88-93.

Schapendonk, J., 2009. Staying put in moving sands: the stepwise migration process of sub-Saharan African migrants heading north. In Respacing Africa. Brill, pp. II3-138.

Spring, A., 2009. African women in the entrepreneurial landscape: Reconsidering the formal and informal sectors. Journal of African Business, I0(I), pp. I I-30.

UBOS \& ICF, 20I8. Uganda Demographic and Health Survey, 2016, Kampala.

UBOS, 2017. The 2016/2017 Uganda National Household Survey, Kampala, Uganda.

UBOS, 2016. The 2014 Uganda National Population and Housing Census, Kampala.

UBOS, 2010. Uganda National Household Survey, 2009/2010, Kampala.

UNDESA, 2015. World population prospects: Key prospects and advance tables. 2015 revision, New York. 